Diana Stellmach, Fanxing Xi, Ulrike Bloeck, Peter Bogdanoff* and Sebastian Fiechter*

\title{
Catalytic Behavior of Molybdenum Sulfide for the Hydrogen Evolution Reaction as a Function of Crystallinity and Particle Size Using Carbon Multiwall Nanotubes as Substrates
}

https://doi.org/10.1515/zpch-2019-1490

Received May 31, 2019; accepted February 10, 2020

\begin{abstract}
Molybdenum sulfide is of interest as a noble metal-free catalyst for the hydrogen evolution reaction (HER). In crystallized form, it shows a typical stacking of planar S-Mo-S layers whereas the catalytically active centers are situated on the edges of these entities characterized by non-saturated bonds of the molybdenum atoms. In this study, $2 \mathrm{H}-\mathrm{MoS}_{2}$ is investigated as HER catalyst as a function of particle size using powder electrodes of different grain sizes and morphology. HER was also determined as a function of growth defects (bending of layers) and as a function of active sites employing $\mathrm{MoS}_{2}$ nanoparticles (NP). To study the influence of the substrate on the perfection of the transition metal disulfide, $\mathrm{MoS}_{2}$ nanosheets were deposited on multi-walled carbon nanotubes (MWCNTs) of different diameters. Highest activity was found for $\mathrm{MoS}_{2}$ nanosheets deposited on MWCNTs with a diameter smaller than $8 \mathrm{~nm}$. At diameters larger than $10 \mathrm{~nm}$, a wrapping of the nanotubes by partially bended stacks of S-Mo-S layers occurs, while at diameters smaller than $10 \mathrm{~nm}$, individual $\mathrm{MoS}_{2}$ nanosheets of 3-5 S-Mo-S stacks of 3-4 $\mathrm{nm}$ in height and $10-20 \mathrm{~nm}$ in lateral extension surround the carbon nanotubes in form of hexagonal cylinders. The ratio of catalytically active non-van-der-Waals and hexagonal basal planes was determined electrochemically by electro-oxidation and correlated with HER activity.
\end{abstract}

Keywords: electro-oxidation; hydrogen evolvution catalyst; molybdenum sulfide; multi wall carbon nanotubes; Raman spectra; reactive center.

\footnotetext{
*Corresponding authors: Peter Bogdanoff and Sebastian Fiechter, Helmholtz-Zentrum Berlin für Materialien und Energie GmbH, Institute Solar Fuels, 14109 Berlin, Germany, e-mail: bogdanoff@helmholtz-berlin.de (P. Bogdanoff); fiechter@helmholtz-berlin.de (S. Fiechter)
}

Diana Stellmach and Fanxing Xi: Helmholtz-Zentrum Berlin für Materialien und Energie GmbH, Institute Solar Fuels, 14109 Berlin, Germany Ulrike Bloeck: Department of Structure and Dynamics of Energy Materials, Helmholtz-Zentrum Berlin für Materialien und Energie, 14109 Berlin, Germany 


\section{Introduction}

Molybdenum disulfide can be used for different applications because of its highly anisotropic layer structure. It is used as a catalyst for the hydrodesulfurization process of crude oil [1], as transistor material using its semiconducting phase [2], but also as a solid lubricant [3]. It occurs in three different layer-type crystal structures, namely $2 \mathrm{H}-\mathrm{MoS}_{2}, 3 \mathrm{R}-\mathrm{MoS}_{2}$ and $1 \mathrm{~T}-\mathrm{MoS}_{2}$. Among them, $2 \mathrm{H}$ and $3 \mathrm{R}$ are the two main phases whereas the $2 \mathrm{H}$ phase is the dominant and most stable phase in nature. As shown in Figure 1, $2 \mathrm{H}-\mathrm{MoS}_{2}$ contains two S-Mo-S layer sequences per unit cell with a trigonal prismatic coordination of the molybdenum atoms by sulfur, while the unit cell of 3R-MoS 2 comprises three layer sequences [4]. The 1T$\mathrm{MoS}_{2}$ phase is characterized by an octahedral coordination of molybdenum by sulfur leading to a metallic property [5, 6]. Bulk $2 \mathrm{H}-\mathrm{MoS}_{2}$ is a compound semiconductor having an indirect band gap of $1.29 \mathrm{eV}$ and a direct one of $1.8 \mathrm{eV}$, which is depending on the number of van der Waals layers in $\mathrm{MoS}_{2}$ [7].

Among the non-precious metal catalysts that have been studied, molybdenum disulfide has stood out for its high catalytic activity of the HER and its high stability, especially under acidic conditions. Interestingly in former studies, $\mathrm{MoS}_{2}$ was thought to only have low catalytic ability for HER [8]. However, according to theoretical calculations, the material should be relatively active for HER since it exhibits modest binding energies with atomic hydrogen and relatively high exchange current density as shown by Jaramillo et al. [9]. In the same paper, the authors describe that the exchange current density of the material is proportional to the edge length of a $\mathrm{MoS}_{2}$ electrode. Therefore, the catalytically active sites of $\mathrm{MoS}_{2}$ are found to be located on the edge site of the hexagonal layers.

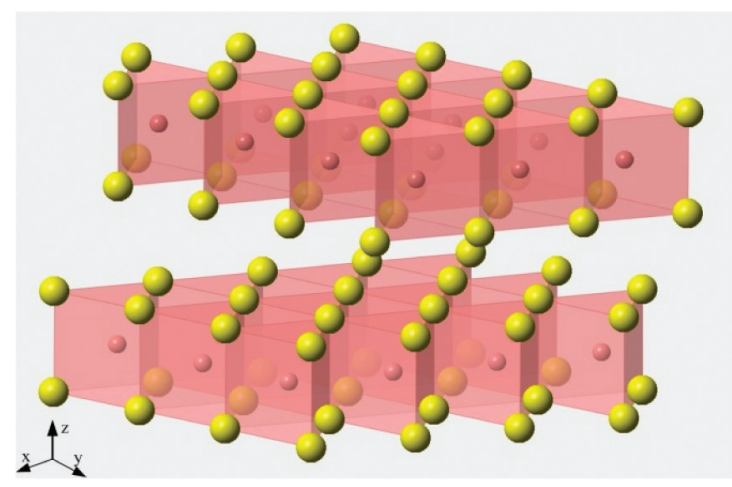

Fig. 1: Crystal structure of hexagonal $\mathrm{MoS}_{2}$ crystallizing in the space group $\mathrm{P}_{3} / \mathrm{mmc}$. 
Since then, researchers have put a lot effort to increase the catalytic ability of $\mathrm{MoS}_{2}$ for HER. One strategy to increase the catalytic activity is simply generating more active sites at the catalyst surface. To achieve this goal, Kibsgaard et al. [10] in 2012 engineered the surface structure of mesoporous $\mathrm{MoS}_{2}$ thin films with a high degree of surface curvature to preferentially expose more edge sites than basal planes, leading to improved catalytic properties. Using high temperature hydrogen annealing, Kiriya et al. [11] discovered that the catalytic ability of different molybdenum sulfides, for instance, bulk, powder and nanoflakes of $\mathrm{MoS}_{2}$, can be increased because of a higher surface area and more active sites due to thermal texturization. In 2016, Li et al. [12] increased the active site number by introducing and straining sulfur vacancies to activate the basal plane of $\mathrm{MoS}_{2}$. DFT calculation suggested higher hydrogen adsorption and optimal Gibbs free energy of hydrogen adsorption $\left(\Delta \mathrm{G}_{\mathrm{H}^{*}}\right)$ in the strained, S-vacancy activated $\mathrm{MoS}_{2}$ catalyst, leading to a lower overpotential $\left(170 \mathrm{mV}\right.$ at $\left.10 \mathrm{~mA} / \mathrm{cm}^{2}\right)$.

Other than modifying the structure of $\mathrm{MoS}_{2}$ itself, molybdenum sulfides with different structures were also studied. For example, cluster-type molybdenum sulfides with a large number of edge atoms per unit area are expected to be a hydrogen evolution catalyst (HEC) of high performance. The incomplete cubane-typed $\left[\mathrm{Mo}_{3} \mathrm{~S}_{4}\right]^{2-}$ cluster was used as HEC in 2008 by Jaramillo et al. The $\left[\mathrm{Mo}_{3} \mathrm{~S}_{4}\right]^{2-}$ cluster obtained a similar overpotential compared with $\mathrm{MoS}_{2}$ NPs of about $300 \mathrm{mV}$ at $-10 \mathrm{~mA} / \mathrm{cm}^{2}$ [13]. Then in 2014, the thiomolybdate cluster $\left[\mathrm{Mo}_{3} \mathrm{~S}_{13}\right]^{2-}$ was described as an efficient HER catalyst with a high number of sulfur atoms located at the edges of the cluster units exhibiting an overpotential of $180 \mathrm{mV}$ at $-10 \mathrm{~mA} / \mathrm{cm}^{2}$ and high stability (10-20 $\mathrm{mV}$ increase of overpotential at $10 \mathrm{~mA} / \mathrm{cm}^{2}$ after 1000 cycles of cyclic voltammetry in the potential range from 0.2 to $-0.3 \mathrm{~V}$ with a $100 \mathrm{mV} / \mathrm{s}$ scan rate) [14].

Besides, amorphous $\mathrm{MoS}_{\mathrm{x}}$ was also discovered for its excellent catalytic activity. The amorphous $\operatorname{MoS}_{\mathrm{x}}$ has a different structure other than layer structured $\mathrm{MoS}_{2}$ which gave the material an unique catalytic behavior. Amorphous $\mathrm{MoS}_{\mathrm{x}}$ can be synthesized through electrodeposition [15], wet chemical reaction [16], and sulfurization without thermal treatment $[17,18]$. The origin of the high catalytic performance of amorphous $\mathrm{MoS}_{\mathrm{x}}$ was not clear for a long time. The high surface area [19] and the existence of bridging and terminal $\left[\mathrm{S}_{2}\right]^{2-}$ were thought to be possible reasons [16]. In 2016, Yeo et al. [20] found that the composition of S species in amorphous $\mathrm{MoS}_{\mathrm{x}}$ was changed during HER. In the meantime, Artero et al. [21] observed loss of terminal $\left[\mathrm{S}_{2}\right]^{2-}$ during HER condition, also suggesting that $\mathrm{MoS}_{\mathrm{x}}$ went through structural changes in HER catalysis process. In the previous study of our group [22], the structural transformation of amorphous $\mathrm{MoS}_{\mathrm{x}}$ from a $\left[\mathrm{Mo}_{3} \mathrm{~S}_{13}\right]^{2-}$ cluster-like material to a $\mathrm{MoS}_{2-\mathrm{x}}$ layer-type material was identified. 
There are still other methods to improve the catalytic ability of molybdenum sulfide. Literatures have already shown that doping $\operatorname{MoS}_{\mathrm{x}}$ with elements such as Co, Fe and Ni could improve its catalytic ability [19]. Besides, by electrochemical exfoliation, the thermodynamically favored $2 \mathrm{H}-\mathrm{MoS}_{2}$ can be partially transformed to a 1T polymorph which has more metallic character and more competitive HER activity [23]. However, even though much progress has been achieved during the past, the catalytic performance of $\mathrm{MoS}_{2}$ as HER catalyst, in both activity and stability, is still much inferior to that of platinum and the catalytic mechanism of $\mathrm{MoS}_{2}$ is partially not yet understood. For this reason, efforts still need to be made for further improvement of its catalytic ability and a detailed understanding of its catalytic mechanism.

In this paper, we compare $\mathrm{MoS}_{2}$ powders of different grain size with $\mathrm{MoS}_{2}$ nanosheets deposited on multi-walled carbon nanotubes (MWCNTs). Owing to two oxidation peaks found in cyclic voltammetry (CV) measurements electrooxidizing $\mathrm{MoS}_{2}$, the area of catalytically active edges of the hexagonal material in contact with the electrolyte can be determined and compared with the areas of the chemically inert basal planes. Using the surfactant Tween 80 , which reacts with unsaturated metal ions located at the layer edges and therefore blocks the active centers, the first oxidation peak has been assigned to the oxidation of the catalytic centers. Thus, the ratio of edge to basal planes in $\mathrm{MoS}_{2}$ can be determined by electrochemical CV measurements.

\section{Experimental}

\section{1 $\mathrm{MoS}_{2}$ electrodes preparation}

\subsection{1 $\mathrm{MoS}_{2}$ preparation}

$\mathrm{MoS}_{2}$ single crystals, used as a reference material in this work, were grown by chemical vapor transport using $\mathrm{MoO}_{3}$ and $\mathrm{IBr}$ as transporting agents. In a first step, $\mathrm{MoS}_{2}(2 \mathrm{~g})$ and $\mathrm{MoO}_{3}$ powder $(25 \mathrm{mg})$ were placed at the closed end of a $190 \mathrm{~mm}$ long and closed quartz glass tube of $20 \mathrm{~mm}$ diameter. Afterwards, the ampoule was evacuated and prior to sealing $\mathrm{IBr}(365 \mathrm{mg}$ ) was sublimed at the cooled end of the ampoule. The tube was placed into a two zone furnace. In a temperature gradient $\Delta \mathrm{T}=1173-1123 \mathrm{~K}$ endothermal transport was observed from hot to cold. After $200 \mathrm{~h}$, crystals up to 5-10 mm edge length were grown in the growth chamber of the ampoule. Crystals investigated in this paper as hydrogen evolving catalysts showed typical growth spirals on the basal planes which have step sizes of several hundred nanometers. 
$\mathrm{MoS}_{2}$ powder (\# DS-315) was prepared by a precipitation reaction dissolving sodium molybdate and thioacetamide in an acid solution: a $10 \mathrm{mM}$ thioacetamid solution dissolved in $1 \mathrm{M} \mathrm{HCl}$ was added to an aqueous $1 \mathrm{mM} \mathrm{Na} 2 \mathrm{MoO}_{4} \cdot 2 \mathrm{H}_{2} \mathrm{O}$ solution. Afterwards, the mixture was stirred for $12 \mathrm{~h}$ and finally the molybdenum sulfide particles were filtered using a PTFE filter. The obtained product was heated in forming gas $\left(10 \% \mathrm{H}_{2}\right.$ in $\left.\mathrm{N}_{2}\right)$ at $450{ }^{\circ} \mathrm{C}$ for $1 \mathrm{~h}$ before the product was heated at $800{ }^{\circ} \mathrm{C}$ for $2 \mathrm{~h}$ under argon gas. The powder sample (\# SF) was synthesized from the elements at $500{ }^{\circ} \mathrm{C}$ in an evacuated and sealed quartz glass ampoule for $50 \mathrm{~h}$ by weighing-in molybdenum and sulfur in the mass ratio of 1:2. The samples Sigma Aldrich I \& II (shortly SA I \& II), Molykote $\mu$-size, and Molykote z-size were purchased from Sigma Aldrich and Dow Chemicals, respectively. The preparation method of these powders is unknown and not specified by the manufacturer. Molykote powders are produced by the manufacturer as lubricants for metals. According to the data sheet, the particle size of the Molykote $\mu$-size preparation is $0.65-0.75 \mu \mathrm{m}$ and that of the Molykote z-powder 3-4 $\mu \mathrm{m}$. According to the supplier the particle size was determined using the Fischer method. The preparation of the samples SA I \& II is also unknown and also the method by which the particle size was determined is not described. Looking at SEM images, a high size distribution of the hexagonal platelets can be seen for all commercial samples. The particles appear to be mechanically fractured and show numerous crystallite fragments (see Figure 2). Sample DS-315 has a particle size of $<200 \mathrm{~nm}$, the particles of the powder \#SF have a particle size ranging from 50 to $1000 \mathrm{~nm}$.

$\mathrm{MoS}_{2}$ grown on MWCNTs was prepared using the same method as described for the preparation of DS-315 powder. In an aqueous $1 \mathrm{mM} \mathrm{Na} \mathrm{MoO}_{4} \cdot 2 \mathrm{H}_{2} \mathrm{O}$ solution $48 \mathrm{mg}$ of MWCNTs were dispersed and ultrasonically homogenized at RT. After $1 \mathrm{~h}$ treatment, a $10 \mathrm{mM}$ thioacetamid solution dissolved in $1 \mathrm{M} \mathrm{HCl}$ was added and homogenized for $2 \mathrm{~h}$ in an ultrasonic bath. Afterwards, the mixture was stirred for $12 \mathrm{~h}$ and finally MWCNT supported molybdenum sulfide was filtered using a PTFE filter. The obtained product was in a first step heated in forming gas $\left(10 \% \mathrm{H}_{2}\right.$ in $\left.\mathrm{N}_{2}\right)$ at $450{ }^{\circ} \mathrm{C}$ for $1 \mathrm{~h}$ and then at $800{ }^{\circ} \mathrm{C}$ for $2 \mathrm{~h}$ under argon gas (Ar).

\subsubsection{Electrode preparation}

Ten milligrams $\mathrm{MoS}_{2}$ powder catalyst or $\mathrm{MoS}_{2}$ catalyst deposited on MWCNT were mixed with $1 \mathrm{~mL}$ poly(3,4-ethylenedioxythiophene) polystyrene sulfonate (PEDOT: PSS), which was diluted before in water in a ratio 0.3:7. After homogenizing the dispersion in an ultrasonic bath, $10 \mu \mathrm{L}$ of the mixture was drop-casted on a FTO substrate of $10 \times 20 \mathrm{~cm}^{2}$ in size. The samples were first dried in air at RT 

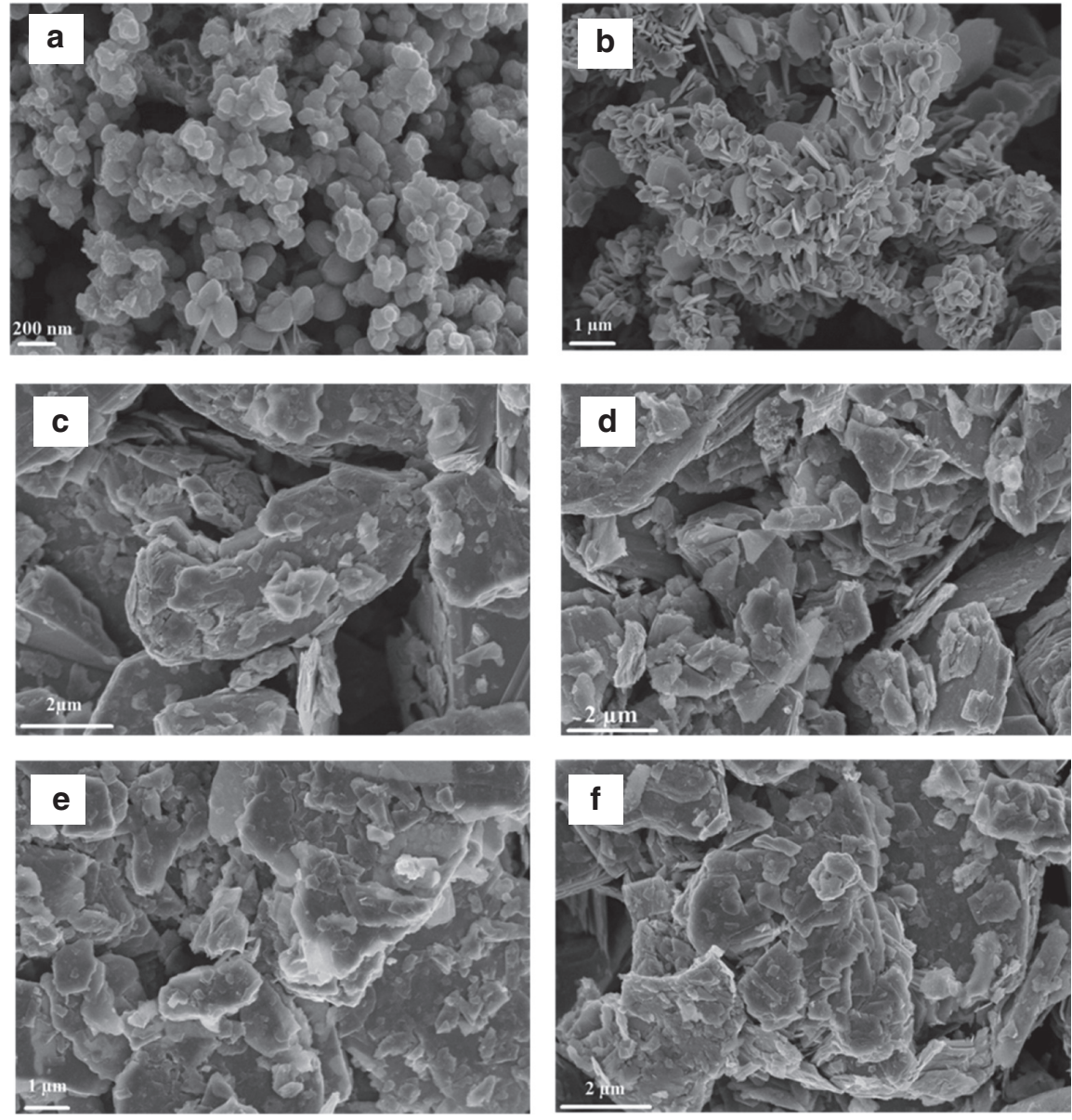

Fig. 2: SEM images of different $M_{2} S_{2}$ powders: (a) DS-315 ( $<200 \mathrm{~nm}$ particle size), (b) SF $(50 \mathrm{~nm}-1000 \mathrm{~nm}),(\mathrm{c})$ Molykote $\mu$-size $(0.65-0.75 \mu \mathrm{m})$, (d) Sigma Aldrich I, (e) Molykote z-powder (mean particle size 3-4 $\mu \mathrm{m})$, and (f) Sigma Aldrich II $(<8 \mu \mathrm{m})$.

and afterwards at $125^{\circ} \mathrm{C}$. To perform XRD measurements, the $\mathrm{MoS}_{2}$ powders and $\mathrm{MoS}_{2}$ deposited on MWCNTs particles were deposited on 111-oriented Si wafers.

\subsection{Structural and morphological characterization}

The morphology of the films was measured by field emission scanning electron microscopy (FESEM) using a LEO GEMINI 1530 instrument from ZEISS, operated with an acceleration voltage of $5 \mathrm{kV}$. For transmission electron microscopy (TEM) analysis, $\mathrm{MoS}_{2}$ catalyst deposited on top of MWCNTs were prepared ultramicrotomically. In the first step, the $\mathrm{MoS}_{2}$ coated nanotubes were embedded in an acryl 
resin (LR-White). Prior to cutting the small polymer blocks by ultramicrotomy (ULTRACUT E from Reichert \& Jung), it was trimmed and acuminated. Ultrathin slices (40-60 $\mathrm{nm}$ thick) were cut from the resin tip and were floated on a water surface from where they were subsequently fixed on carbon film covered grids. Alternatively, small slices ( $0.5 \mathrm{~mm}$ thick) were cut from the tiny resin block and glued face to face. Afterwards these samples were sanded and polished perpendicular to the glued interface down to a thickness of 4-6 $\mu \mathrm{m}$ before they were fixed to a molybdenum ring. At the end the samples were ion-milled ( $5 \mathrm{kV}, 2 \mathrm{~mA})$ using Ar ions under an incidence angle of $6^{\circ}$ until parts of the sample became transparent for the electron beam. Finally, the so prepared samples were investigated by a transmission electron microscope ( $\mathrm{Cm} 12$ from Philips, equipped with $\mathrm{a} \mathrm{LaB}_{6}$ cathode) and electron micrographs were taken at an acceleration voltage of $120 \mathrm{kV}$. A Bruker AXS D8 Advance X-ray diffractometer with $\mathrm{Cu}$ K $\alpha$ radiation $(\lambda=0.15406 \mathrm{~nm})$ was used to obtain glancing incidence X-ray diffractiongrams (GIXRD). The angle of incidence was $0.5^{\circ}$ and the measured detection angle (2 $\theta$ ) was varied from $10^{\circ}$ to $60^{\circ}$. Raman spectroscopy was performed using a LabRam spectrometer from Horiba Jobin Yvon under excitation conditions using a $\mathrm{He} / \mathrm{Ne}$ laser with $\lambda=632.82 \mathrm{~nm}$, which was focused via a microscope (Olympus BX 40) on the surface of the samples. A CCD camera detected the Raman peaks.

\subsection{Electrochemical measurements}

Cyclic voltammetry (CV) measurements were performed using a VersaSTAT3 potentiostat in a three-electrode configuration. $\mathrm{MoS}_{2}$ electrodes deposited on FTO were used as working electrodes (WE) while an $\mathrm{Ag} / \mathrm{AgCl}$ electrode in saturated $\mathrm{KCl}$ solution $(-0.197 \mathrm{~V}$ vs. reversible hydrogen electrode (RHE)) served as reference electrode (RE), and a platinum wire as counter electrode (CE). The electrolyte

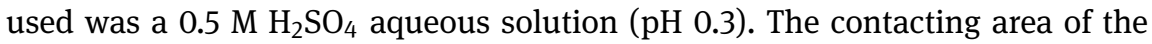
sample with the electrolyte was fixed using an O-ring of $0.63 \mathrm{~cm}$ diameter which is equivalent to an electrode area of $0.3117 \mathrm{~cm}^{2}$. The $\mathrm{iR}$ drop of the sample in the electrolyte was calculated by measuring the resistance of the sample in the electrolyte at $100 \mathrm{kHz}$ using electrochemical impedance spectroscopy (EIS). The current density was evaluated from cyclic voltammetry (CV) measurements. The $\mathrm{CV}$ measurements were performed within the potential range from $0.6 \mathrm{~V}$ to $-0.4 \mathrm{~V}$ vs. RHE with a scan rate of $10 \mathrm{mV} / \mathrm{s}$. The double layer capacitance $\left(\mathrm{C}_{\mathrm{dl}}\right)$ of the $\mathrm{CV}$ curves shown in Figure 4 and Figure 8 were extracted calculating $\Delta j=j_{\mathrm{a}}-j_{\mathrm{c}}\left(j_{\mathrm{a}}\right.$ and $j_{\mathrm{c}}$ represent anodic and cathodic current densities) at a potential $\mathrm{U}=0 \mathrm{~V}$ using the equation $j_{\mathrm{a}}-j_{\mathrm{c}}=\mathrm{C}_{\mathrm{dl}} \mathrm{dU} / \mathrm{dt}$. The obtained value was added to the $j_{\mathrm{c}}-\mathrm{V}$ curves. The corrected curves are shown in the Figures S2 and S3 of the Supplementary information. The edge sites of the $\mathrm{MoS}_{2}$ nanoparticles were catalytically 
passivated by immersing the electrodes in $5 \mathrm{~m} \%$ Tween 80 solution for 2 days under continuous stirring.

\section{Results and discussion}

\section{1 $\mathrm{MoS}_{2}$ powder electrodes}

Six kinds of $\mathrm{MoS}_{2}$ powders were compared with each other with respect to their HER activity. The morphology of the electrodes prepared from different $\mathrm{MoS}_{2}$ powders is shown in the SEM images of Figure 2. According to the morphology, sample DS-315 has the smallest and most isotropic particle sizes ranging from 100 to $200 \mathrm{~nm}$ (Figure 2a). The typical platelet-like hexagonal growth features of $2 \mathrm{H}$ $\mathrm{MoS}_{2}$ occur in the powder sample \#SF (Figure 2b). The other four commercial samples (Figure 2c-e) have a totally different morphology. Their shapes point at fractured hexagonal platelets with 1-10 $\mu \mathrm{m}$ extension of the (001) facets. Therefore, it is difficult to predict which of these samples has the highest fraction of small $\mathrm{MoS}_{2}$ fragments.

According to the XRD patterns in Figure 3a, all six powders show the typical diffraction pattern of $2 \mathrm{H}-\mathrm{MoS}_{2}$. However, sample DS-315 also shows peaks of $\mathrm{MoO}_{2}$ which could be from the residual reactant sodium molybdate $\left(\mathrm{Na}_{2} \mathrm{MoO}_{4}\right)$. The increasing intensity of the 00.2 diffraction peak at $14.4^{\circ} \mathrm{C}$ in the XRD patterns represents an increasing crystallinity. Sample DS-315 has the lowest peak intensity and highest full width half maximum (FWHM), which means that the sample
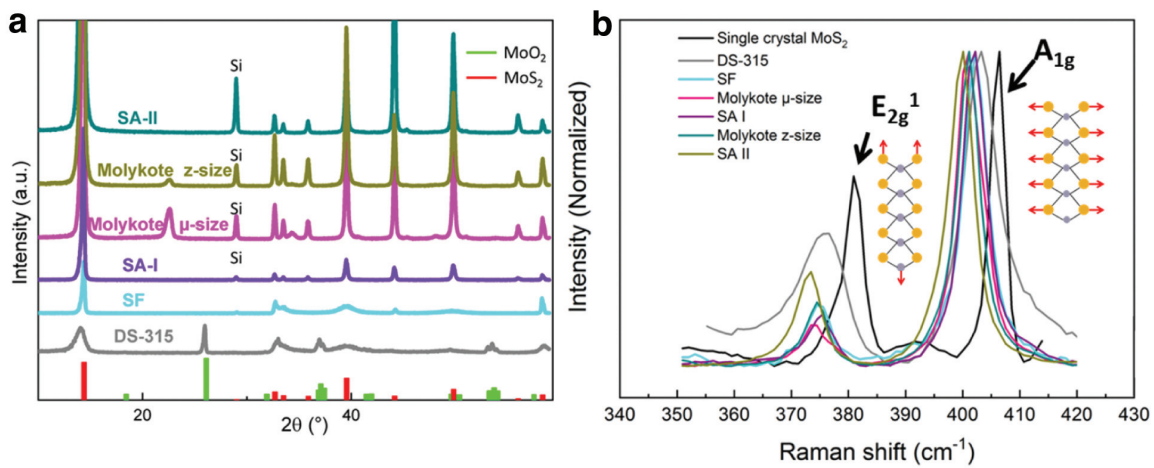

Fig. 3: (a) XRD patterns of $\mathrm{MoS}_{2}$ powders with standard $2 \mathrm{H}-\mathrm{MoS}_{2}$ pattern (red) and $\mathrm{MoO}_{2}$ pattern (green) displayed at the bottom of the figure; (b) Raman spectra of different $\mathrm{MoS}_{2}$ powders including commercial products (Sigma Aldrich I (SA I), Sigma Aldrich II (SA II), Molykote z-size, Molykote $\mu$-size), $M_{0} S_{2}$ prepared by precipitation (DS-315), and chemical synthesis under vacuum (SF), in relation to a $\mathrm{MoS}_{2}$ single crystal. In addition, schemes for the vibrational modes $\left(E_{2 g}{ }^{1}\right.$ and $\left.A_{1 g}\right)$ of hexagonal $M_{0} S_{2}$ are shown. 
has lower crystallinity and smaller particle sizes as compared to the other five samples.

In addition, the 00.2 peak is slightly shifted to a smaller $2 \theta$-value of about $0.35^{\circ}$ indicating an increased distance between the S-Mo-S layers unities due to a disturbed stacking of the S-Mo-S slabs. The 10.1 peak appears to be shifted to a higher $2 \theta$-value pointing at a smaller $\mathrm{a}_{\mathrm{o}}$ lattice constant possibly caused by sulfur point defects. Using Scherrer's equation, coherently scattering crystallites of about $7 \mathrm{~nm}$ in height were determined from the broadening of the 00.2 peak which relates to about twelve $\mathrm{S}-\mathrm{Mo}-\mathrm{S}$ stacks.

Figure $3 \mathrm{~b}$ shows the Raman spectra of the $\mathrm{MoS}_{2}$ powders. In this figure, $\mathrm{a} \mathrm{MoS}_{2}$ single crystal was used as reference material. Its Raman spectrum shows strong characteristic peaks at $382 \mathrm{~cm}^{-1}$ due to in-plane vibration of Mo-S bonding in the layer structure of $2 \mathrm{H}-\mathrm{MoS}_{2}$, namely $\mathrm{E}_{2 \mathrm{~g}}{ }^{1}$ mode and at $407 \mathrm{~cm}^{-1}$ owing to an out of plane vibration of the $\mathrm{S}-\mathrm{S}$ bonding, which could be assigned as $\mathrm{A}_{1 \mathrm{~g}}$ mode (see scheme in Figure 3b) [24-26]. All powder samples show a red shift of the $E_{2 \mathrm{~g}}{ }^{1}$ peak by $8 \mathrm{~cm}^{-1}$ and of the $\mathrm{A}_{1 \mathrm{~g}}$ mode by $7 \mathrm{~cm}^{-1}$ and additional broadening of the peaks. In general, the peak shift and broadening of the Raman peaks could be affected by different factors, such as crystallite size [27], numbers of stacked S-Mo-S layer entities or extension of the van-der-Waals surface area [28], strain in the layers [29], changes in composition [30], and degree of oxidation [31].

$\mathrm{CV}$ measurements were used to investigate the electrochemical activity of the $\mathrm{MoS}_{2}$ powders. Figure 4a shows the CV curves of the powder electrodes. The sample DS-315, which has the smallest particle size according to the morphology shown in Figure 2a, exhibited the highest current density $\left(1 \mathrm{~mA} \mathrm{~cm}^{-2}\right.$ at a potential of $-0.3 \mathrm{~V}$ vs. RHE) owing to small areas of the (00.1) basal planes but a large number of sulfur determined edges ((hk.0) facets). Interestingly, the catalytic
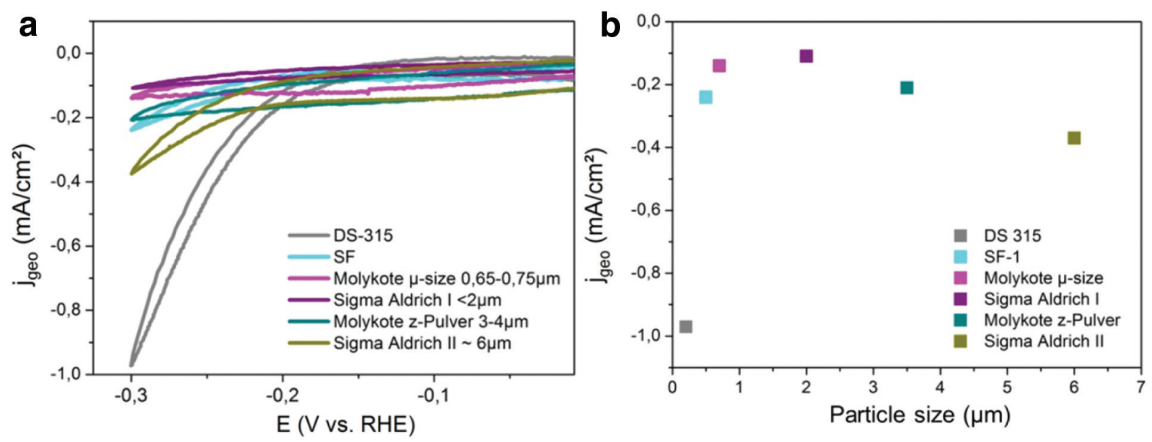

Fig. 4: (a) CV curves of the $\mathrm{MoS}_{2}$ powder electrodes; measured in $0.5 \mathrm{M} \mathrm{H}_{2} \mathrm{SO}_{4}$ at a scan rate of $10 \mathrm{mV} / \mathrm{s}$; the data were iR-corrected according to the procedure described in the experimental section; for $C_{d l}$ corrected curves see Figure S2; (b) dependence of the current density at $-0.3 \mathrm{~V}$ vs. RHE on particle size, the data were taken from Figure 4 (a). 
activity of sample \#SF is worse than that of the commercial powder SA II, indicating that the number of active sites in sample SA II is higher although its mean particle size is much larger. This effect could be explained by a high number of smaller fragments in this sample which is underestimated in the particle size determination from Figure 2f. Figure 4b shows the current density of different electrodes at the reversal point of the potential scan at $-0.3 \mathrm{~V}$ vs. RHE as a function of particle size of the $\mathrm{MoS}_{2}$ powder. At this highest applied potential the Faraday current has the largest contribution to the measured total current, so that it is the most suitable point for a comparison of the HER activity. It should be noted, however, that these data also include a certain amount of capacitive effects (see corrected curves in Figures S2 and S3). The current density of the electrode increases strongly as soon as the particle size becomes smaller than $1 \mu \mathrm{m}$. This result is in consistent with the fact that only the edge sites of $\mathrm{MoS}_{2}$ layers are catalytically active.

\section{2 $\mathrm{MoS}_{2}$ deposited on MWCNTs}

In order to further increase the area of non-van-der-Waals planes where the catalytically active centers are located, $\mathrm{MoS}_{2}$ nanosheets were grown by the precipitation reaction described above on MWCNT substrates of different diameters. Four different series of samples were produced varying the MWCNT diameter from $<8 \mathrm{~nm}$ to $\geq 50 \mathrm{~nm}$. The diameters of the MWCNTs used as substrates for $\mathrm{MoS}_{2}$ nanosheets, namely ARKM00x, are shown in Table 1.

The $\mathrm{MoS}_{2}$ samples deposited on MWCNTs were compared with the DS-315 powder sample prepared by the same protocol. According to the XRD patterns in Figure 5, they all show both the 00.2-reflection and the representative reflections of (hk.0) and (h0.l) lattice planes as well. The (hk.0) reflections referred to lattice planes parallel to the c-axis of related crystallites. In case of (h0.1) reflections, the planes intersect the $\mathrm{a}_{0}$ - as well as the $\mathrm{c}_{0}$-axis. In addition to the characteristics of $\mathrm{MoS}_{2}$, the XRD patterns also exhibit peaks belonging to $\mathrm{MoO}_{2}$. The presence of this phase can be explained by residual reactant sodium molybdate $\left(\mathrm{Na}_{2} \mathrm{MoO}_{4}\right)$ in the

Tab. 1: The diameters of MWCNTs used as carriers for $\mathrm{MoS}_{2}$.

\begin{tabular}{lr}
\hline MWCNT & Diameter (nm) \\
\hline ARKM001 & $<8$ \\
ARKM002 & $10-20$ \\
ARKM004 & $40-50$ \\
ARKM005 & $>50$ \\
\hline
\end{tabular}



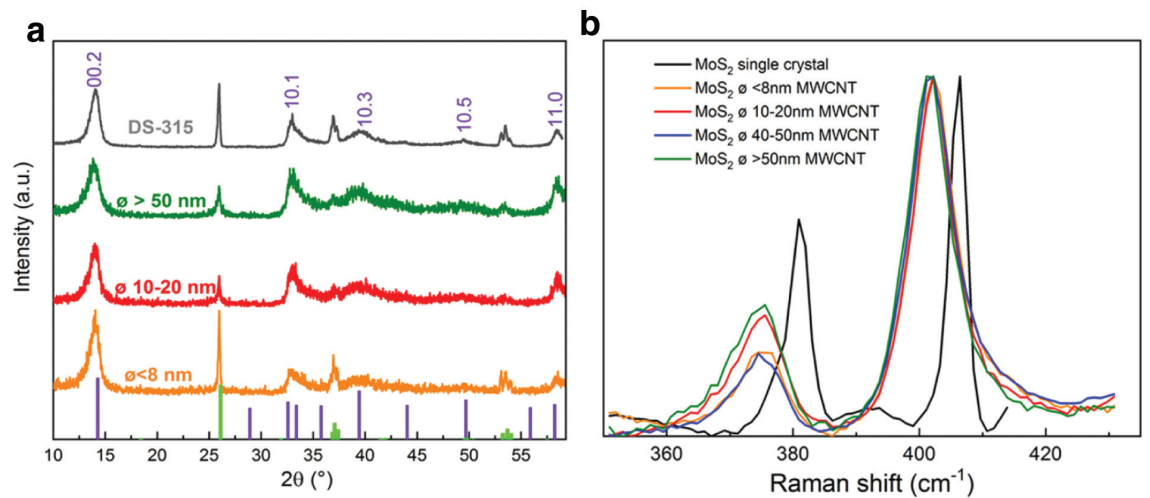

Fig. 5: (a) XRD of $\mathrm{MoS}_{2}$ layers on MWCNTs with various tube diameters: ARKM001 $\varnothing<8 \mathrm{~nm}$, ARKM002 $\varnothing 10-20 \mathrm{~nm}$, ARKM005 $\varnothing>50 \mathrm{~nm}$. Standard patterns of $2 \mathrm{H}-\mathrm{MoS}_{2}$ (purple) and $\mathrm{MoO}_{2}$ (green) are shown on the bottom of the graph; (b) Raman spectra of $\mathrm{MoS}_{2}$ nanosheets deposited on MWCNTs, compared with $\mathrm{MoS}_{2}$ single crystal.

batch or by a partial oxidation of the nanosheets in contact with air. Figure 5b displays the corresponding Raman spectra of $\mathrm{MoS}_{2}$ deposited on different MWCNTs. All samples show the $\mathrm{MoS}_{2}$ typical vibrational modes, which could be addressed as $\mathrm{E}_{2 \mathrm{~g}}{ }^{1}$ and $\mathrm{A}_{1 \mathrm{~g}}$. Compared with the Raman spectrum of a $\mathrm{MoS}_{2}$ single crystal they are red shifted and show a broadening of the peaks indicating structural defects, partial oxidation or deviations from stoichiometry as also discussed in Figure $3 \mathrm{~b}$ [27, 29, 31-34]. In Figure S1 of the supporting information, the Raman spectra of the MWCNT supports are also shown. From the spectra it can be concluded that the most perfect nanotubes had a diameter $\leq 8 \mathrm{~nm}[35,36]$. As explained in the following, structural nanotube perfection presumably does indirectly influence the performance of the HER catalyst (see below).

Figure 6 shows four TEM images of $\mathrm{MoS}_{2}$ deposited on MWCNTs (diameters ranging from 20 to $40 \mathrm{~nm}$ ) in transverse and longitudinal cross sections. As shown, $\mathrm{MoS}_{2}$ nanosheets surround MWCNTs whereas S-Mo-S layer units appear as stacks of distinctive bold black lines on the MWCNT substrates. The carbon layers beneath are represented as black lines of lower intensity and thickness. Besides, the line distances can also be used to distinguish $\mathrm{MoS}_{2}$ from the carbon substrate. Graphite like MWCNT has a lattice distance of around $3.4 \AA$ while $2 \mathrm{H}-\mathrm{MoS}_{2}$ is characterized by a S-Mo-S layer distance of around $6.4 \AA$ [10]. The $\mathrm{MoS}_{2}$ nanosheets partially adapt to the bending of the carbon nanotubes, but in most cases the $\mathrm{MoS}_{2}$ nanosheets show no bending and appear as individual flat $\mathrm{MoS}_{2}$ nanosheets showing small extension of the (00.1) planes compared to the nanosheet thickness. This observation is consistent with the model that the 

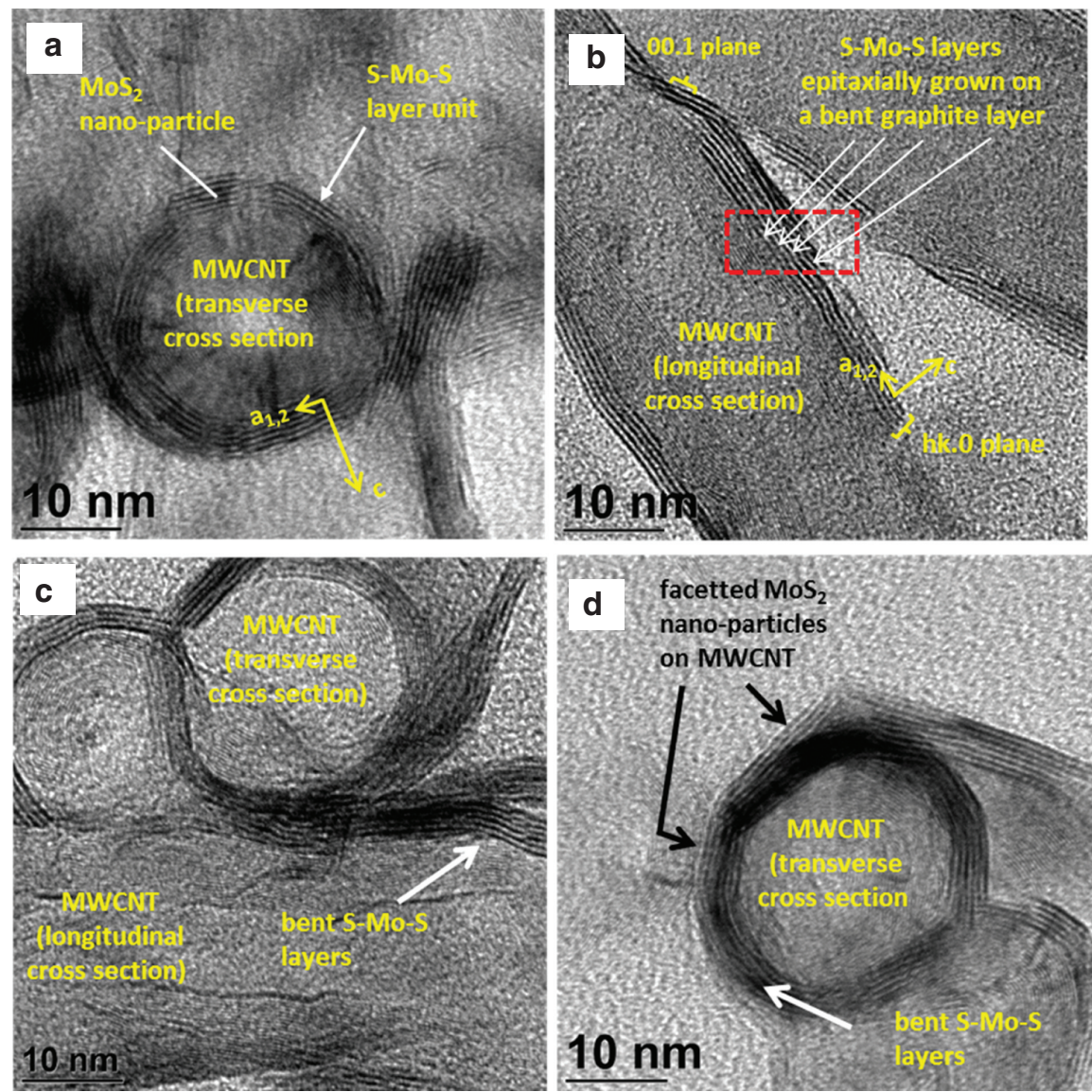

Fig. 6: TEM images of transverse and longitudinal cross sections of MWCNTs surrounded by S-Mo-S layer stacks. (a) Unbent S-Mo-S stacks with gaps between the particles with an extension of $5-10 \mathrm{~nm}$, (b) slightly bent S-Mo-S units with a length $<30 \mathrm{~nm}$ which are oriented parallel to carbon fibers, (c) facetted growth of $\mathrm{MoS}_{2}$ nanoparticles enveloping a multiwall carbon nanofiber, (d) partly bent $\mathrm{MoS}_{2}$ particles enveloping a carbon fiber.

bending behavior of $\mathrm{MoS}_{2}$ is limited as shown schematically in Figure 7. As a consequence, $\mathrm{MoS}_{2}$ nanosheets are separated from each other by a small gap with decreasing MWCNT diameter (see Figure 6a). The surfaces of the S-Mo-S layers are $10 \mathrm{~nm}-20 \mathrm{~nm}$ broad and at least $50 \mathrm{~nm}$ long, the S-Mo-S stack number varies from 1 to 7 layer units. Encapsulation of MWCNTs by stacks of S-Mo-S layers can be understood as a hexagonal cylinder enclosing the individual carbon nanotubes under ideal conditions. Ideally, the gaps between the individual nanosheets are expected be large enough that protons in the electrolyte have access to the edges 


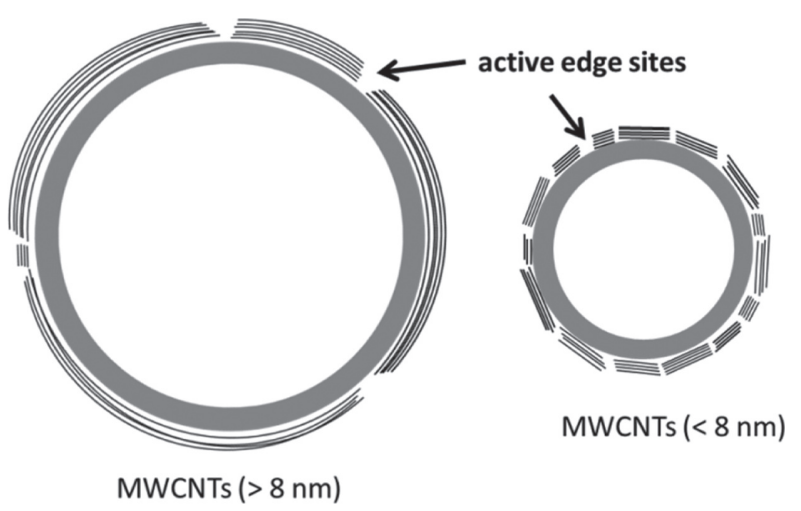

Fig. 7: Scheme of $\mathrm{MoS}_{2}$ nanosheets grown on MWCNT substrates with different diameters.

of the S-Mo-S units. Best catalytic material is expected to have a high stacking number of S-Mo-S entities which then offer a large number of reactive sites at the particle electrolyte.

Figure 8a shows the catalytic activity of the $\mathrm{MoS}_{2}$ grown on MWCNTs. As already explained in Figure 4, again a splitting of the curves between the forward and reverse scan due to capacitive effects can be seen. The capacitance corrected curves are shown in Figure S3. The sample deposited on the smallest diameter MWCNTs $(<8 \mathrm{~nm})$ obtained a current density of $2 \mathrm{~mA} / \mathrm{cm}^{2}$ at the potential of $-0.3 \mathrm{~V}$ vs. RHE, which is the highest activity. The current densities of the other samples at the same potential are ranging from 1.4 to $1.0 \mathrm{~mA} / \mathrm{cm}^{2}$. The light grey
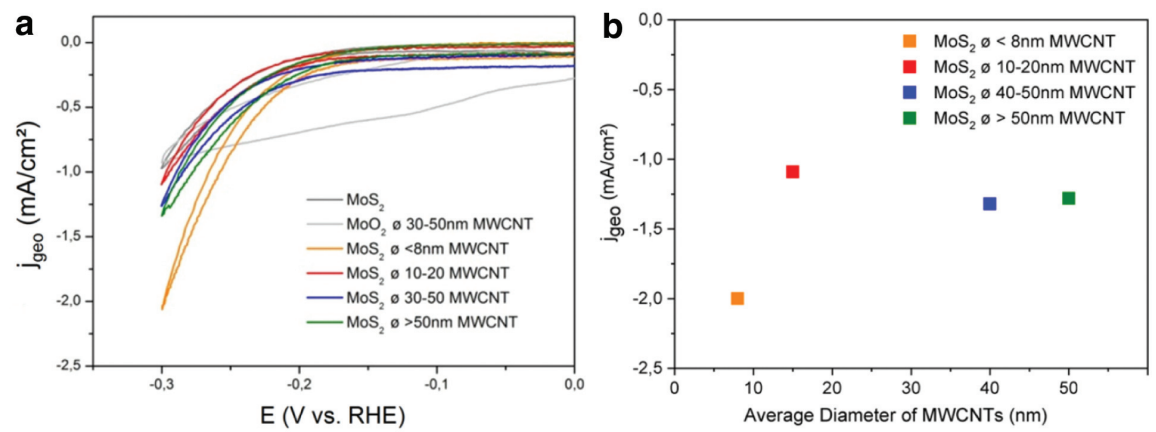

Fig. 8: (a) CV-curves of MWCNT supported MoS2 nanoparticles in comparison to DS-315 and a pure $\mathrm{MoO} 2$ electrode; data were measured in $0.5 \mathrm{M} \mathrm{H}_{2} \mathrm{SO}_{4}$ with a scan rate of $10 \mathrm{mV} / \mathrm{s}$; the data were iR-corrected according to the procedure described in the experimental section; for $C_{d l}$ corrected curves see Figure S3; (b) dependency of the current density at a voltage of $-0.3 \mathrm{~V}$ vs. RHE as a function of the diameter of MWCNTs; data were taken from Figure 8 (a). 
curve shows the $\mathrm{CV}$ curve of $\mathrm{MoO}_{2}$ which proves that this phase has only a moderate catalytic activity. In neither the $\mathrm{MoS}_{2}$ powders nor the $\mathrm{MoS}_{2}$ layer sequences grown on the carbon MWCNTs, hydrogen sulfide evolution $\left(\mathrm{H}_{2} \mathrm{~S}\right)$ as a corrosion product has been detected investigating the released gases by a mass spectrometer coupled to our electrochemical cell. Figure $8 \mathrm{~b}$ shows the current density as a function of the average diameter of MWCNTs at a potential of $-0.3 \mathrm{~V}$ vs. RHE. As explained above (see Figure 4) at this highest applied potential the Faraday current has the highest contribution to the overall current density. The result is comparable to the dependence of the current density of $\mathrm{MoS}_{2}$ powders on the particle size (see Figure 4b). In the case of $\mathrm{MoS}_{2}$ deposited on MWCNTs of $8 \mathrm{~nm}$ diameter, the improved catalytic performance can be explained by a higher number of catalytic sites at the edges of S-Mo-S units owing to a higher number of stacks which are accessible by the electrolyte. To prove this assumption, clarification of the catalytic centers in different $\mathrm{MoS}_{2}$ electrodes were investigated by electro-oxidation.

Since $\mathrm{MoS}_{2}$ is highly anisotropic the question arises how far the electrical conductivity influences the catalytic behavior considering changes of the particle dimension and the orientation of the nanosheets with respect to the carbon nanotubes. It is known that bulk $2 \mathrm{H}-\mathrm{MoS}_{2}$ is a compound semiconductor with an indirect band gap of $E_{g}=1.4 \mathrm{eV}$ followed by a direct one at $E_{g}=1.9 \mathrm{eV}$. In 1983, Thakurta and Dutta studied the specific conductance of highly doped natural crystals perpendicular $\left(\mathrm{s}_{\perp}\right)$ and parallel $\left(\mathrm{s}_{\|}\right)$to the hexagonal c-axis [37]. They found a specific conductance for $\mathrm{s}_{\perp}$ ranging from $0.078-1.09 \mathrm{~W}^{-1} \mathrm{~cm}^{-1}$ while $\mathrm{s}_{\perp}$ was four orders of magnitude smaller ranging from 3.0-4.6 $\times 10^{-4} \mathrm{~W}^{-1} \mathrm{~cm}^{-1}$. This means that the conductivity parallel to the hexagonal surface is high compared to the conductivity perpendicular to the hexagonal c-axis. Since the number of S-Mo-S is typically four to seven in our case (see Figure 6) electron transport from the carbon tubes via the stacked S-Mo-S layers to the catalytically active centers is small compared the conductivity in the S-Mo-S layers. This means that both particle dimension and number of stacks determine the transport velocity of electrons from the carbon nanotube via the $\mathrm{MoS}_{2}$ nanosheets to the catalytically active centers. Since in our MWCNT supported $\mathrm{MoS}_{2}$ catalyst nanoparticles the SMo-S stacking number did not change when lowering the particle extension of the 00.1 facets the number of edges is mainly determining the catalytic performance as will be discussed and demonstrated in the following chapter.

\subsection{Clarification of the catalytic center by electro-oxidation}

Bonde et al. [32] analyzed $\mathrm{MoS}_{2}$ samples by a surface-sensitive method, X-ray photoelectron microscopy (XPS) before and after electro-oxidation. They could show 
that the intensities of the Mo $3 d$ and Mo $3 p$ signals as well as the S $2 s$ and S $2 p$ decreased after the experiment. This can be explained by a number of reasons: a) $\mathrm{MoS}_{2}$ could delaminate from the surface of the conductive support or b) $\mathrm{MoS}_{2}$ is oxidized to $\mathrm{MoO}_{3}\left(\mathrm{Mo}^{3+}\right)$ which could be soluble in the electrolyte. According to the work of n-type photoactive $\mathrm{MoS}_{2}$ single crystals, sulfur compounds such as $\mathrm{SO}_{4}{ }^{2-}, \mathrm{S}_{2}{ }^{2-}$ and $\mathrm{MoO}_{3}$ are formed after electrochemical measurements in potassium nitrate $\left(\mathrm{KNO}_{3}\right)$ [38].

The reaction equation of the oxidation at the edges can be expressed by the equation [32]:

$$
\mathrm{MoS}_{2}+7 \mathrm{H}_{2} \mathrm{O} \rightarrow \mathrm{MoO}_{3}+\mathrm{SO}_{4}{ }^{2-}+\frac{1}{2} \mathrm{~S}_{2}{ }^{2-}+14 \mathrm{H}^{+}+11 e^{-}
$$

According to the literature [9], the catalytically active centers of molybdenum disulfide are located at Mo atoms piercing out of hk.0 and h0.l surfaces of the crystalline material. Since the edge Mo atoms with dangling bonds and Mo atoms of complete coordination of sulfur sandwiched between sulfur layers (basal planes) have different electrochemical properties, the electro-oxidation of these two kinds of atoms should appear as two separate peaks in CV curves under anodic conditions. Therefore by electro-oxidation, the edges should be distinguishable from basal planes. This process could be verified by passivating the edges with a nonionic surfactant, e.g. Tween 80 as demonstrated in the following discussion.

In our study electro-oxidation is performed using $\mathrm{MoS}_{2}$ nanosheets grown on MWCNTs. The edge-basal plane-ratio of the samples has been determined by electro-oxidation and the correlation between the current density and the edge-basal plane-ratio is discussed.

\subsubsection{Passivation of the edges with Tween $\mathbf{8 0}$}

By treating a HEC characterized by a layer structure with organic detergents, the $\mathrm{CV}$ characteristics can be influenced, since the detergents are specifically attaching to the reactive edges of the individual layer units. To investigate this behavior, organic detergents with ligands that act as electron donors and molecules with large functional groups, which affect and limit the reaction due to steric hindrance, are used. Chemical treatment of photocatalysts were first described by Parkinson et al. [39]. In their experiments, treatments with organic ligands such as 1,2-bis (diphenylphosphino) ethane (diphos), which is commonly used for rodium-catalyzed hydroformylation [40], showed a lower dark current and a higher open-circuit voltage. In the treatment of tungsten diselenide $\left(\mathrm{WSe}_{2}\right) \sin$ gle crystals, the phosphorous atom of the diphos reacts with tungsten atoms at 
the edges or on steps of (00.l) facets of hexagonal crystals. Other ligands such as isocyanides, thiocarbamates [41], ethylenediamine tetraacetate (EDTA) [42], and 1,2-diaminobenzene (OPD) [43], also show a reduction of the dark current due to passivation of recombination centers on the (00.1) planes and crystal edges.

In this work, the nonionic surfactant Tween 80 , which is used as an oil/water emulsifier [44], was chosen as passivation material. Tween 80 is an ethoxylated sorbitan fatty acid ester with the trade name Tween. The structure of Tween 80 is shown in Figure 9. The sorbitans differ in their fatty acid, the middle number of the polyoxyethylene units of the molecule, and the degree of esterification. In Tween 80 , the number 8 stands for the oleic acid and number 0 stands for a monoester with 20 polyethylene units.

After the $\mathrm{MoS}_{2}$ samples were impregnated with Tween 80, the influence of the surfactant on the catalytic activity has been investigated by electrochemical measurements. After treatment of $\mathrm{MoS}_{2}$ with Tween 80, the surfactant covers the edges of the S-Mo-S slabs, which are considered as the reaction centers for the HER. This experiment can additionally clarify the meaning of the oxidation peaks in the CV curves shown below (Figure 11), which are attributed to an electro-oxidation of the catalyst.

Figure 10 shows the $\mathrm{CV}$ characteristic of a $\mathrm{MoS}_{2}$ single crystal in the potential range from $0.6 \mathrm{~V}$ to $-0.4 \mathrm{~V}$ vs. RHE with and without Tween 80 . The initial cycle was measured up to a potential of $1.7 \mathrm{~V}$ vs. RHE to clean the surface. This effect is noticeable in Figure 10 by an increased current density in the following CV cycles as shown by the black arrow. The current density of the $\mathrm{MoS}_{2}$ single crystal electrode after cleaning is about $0.5 \mathrm{~mA} / \mathrm{cm}^{2}$ at $-0.4 \mathrm{~V}$ vs. RHE. After passivation of the active sites by Tween 80 , the current density reduces to $-0.05 \mathrm{~mA} / \mathrm{cm}^{2}$ at the same potential (orange curve in Figure 10). As the number of CV cycles increases, the current density in hydrogen evolution of the sample treated with Tween

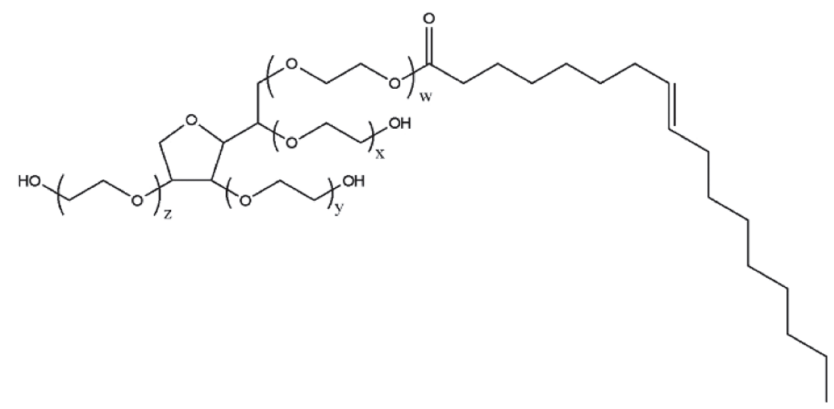

Fig. 9: Structure of the non-ionic surfactant Tween $80(w+x+y+z=20)$. 


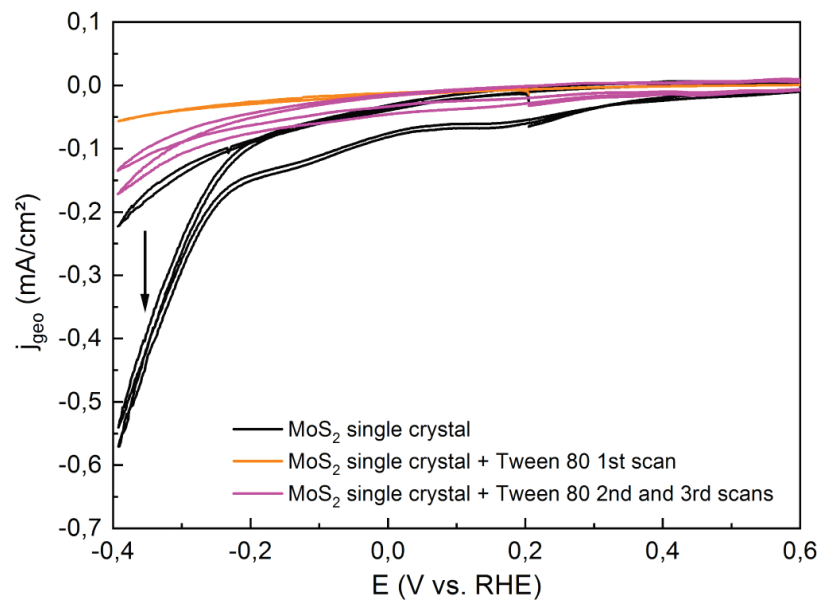

Fig. 10: $\mathrm{CV}$ curve of a $\mathrm{MoS}_{2}$ single crystal before (black curve) and after impregnation with Tween 80 (orange and pink curves). All curves are iR-corrected as described in the experimental section.

80 increases as well. The surfactant is apparently reversibly coordinating the edges.

Figure 11a displays the CV curve of $\mathrm{MoS}_{2}$ nanosheets grown on ARKM005 MWCNTs (diameter $>50 \mathrm{~nm}$ ) with and without Tween 80 taken in the positive potential range. The surfactant slightly also alters the second oxidation peak since the surfactant partially covers the (00.1) surfaces. However, the intensity of the first oxidation peak is significantly reduced after the treatment with Tween 80 and the peak position is shifted by about $50 \mathrm{mV}$ (see Figure 11b). According to the CV of the electrode before and after the treatment with Tween 80 in Figure 11c, Tween 80 is obviously attached to the edge sites of S-Mo-S entities passivating the catalytically active centers because the current density at negative potential decreases dramatically, which was also found for the $\mathrm{MoS}_{2}$ single crystal (see Figure 9). From the change of the two electro-oxidation peaks in Figure 11a, it can be concluded that the first electro-oxidation peak is connected with an oxidation of the edge sites while the second peak is correlated to the oxidation of the basal planes. Since the first peak is still visible after the treatment of Tween 80, only a part of the catalytically active centers was passivated by Tween 80 . The reason could be that the surfactant has a large steric hindrance due to the presence of the polyoxoethylene group. Therefore, it is not able to coordinate to all metal atoms at the $\mathrm{MoS}_{2}$ edges. This fact is also the reason why the evolution of hydrogen of the cathode does not completely disappear after Tween 80 treatment in Figure 11c. 

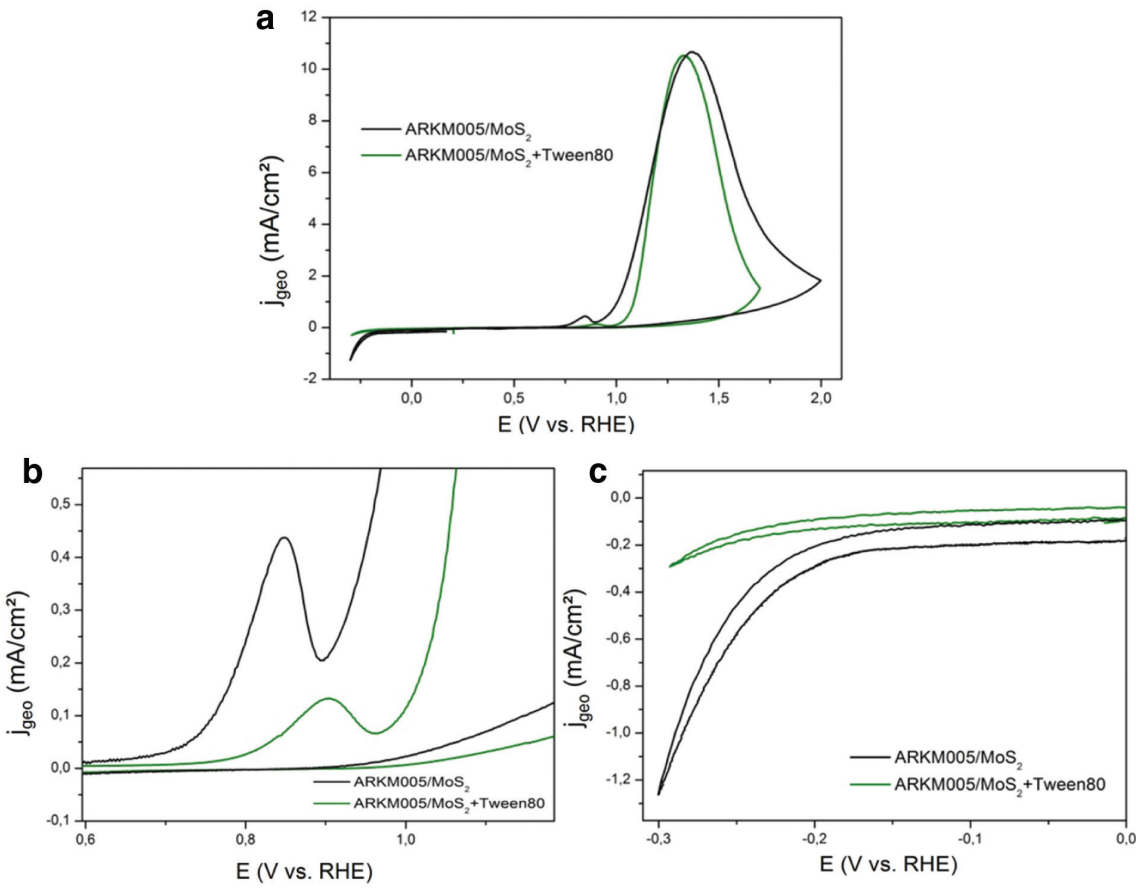

Fig. 11: Passivation of the edges of the S-Mo-S nanosheets of $\mathrm{MoS}_{2}$ nano-particles deposited on MWCNTs (ARKM005 $\varnothing>50 \mathrm{~nm}$ ) with Tween 80: (a) oxidation behavior at a glance: (b) oxidation behavior of the first peak before and after treatment with TWEEN 80 magnified and (c) HER behavior of the electrode before (black curve) and after treatment with TWEEN 80 (green curve). All curves are iR-corrected by the procedure described in the experimental section.

\subsubsection{Electro-oxidation of $\mathrm{MoS}_{2}$ nanosheets grown on MWCNTs with different diameters}

Since the edges and basal planes in $\mathrm{MoS}_{2}$ can be identified and also quantified by electro-oxidation, the catalytic properties of $\mathrm{MoS}_{2}$ nanosheets grown on MWCNTs of different diameter were studied by CV. In this study, the correlations between the current density and the edge-to-basal-plane-ratio for $\mathrm{MoS}_{2}$ nanosheets deposited on MWCNTs were determined.

Table 2 shows the calculated area of the first (A1) and the second (A2) electrooxidation peak, respectively, as well as the edge-to-basal-plane ratio for different MWCNT/MoS 2 electrodes. According to Table 2, the four MWCNT/MoS 2 samples with different diameters have similar $A 2$ values, suggesting similar basal plane areas. However, the $A 1$ value of $\mathrm{ARKMO01} / \mathrm{MoS}_{2}$ was significantly higher 
Tab. 2: Calculation of peak areas and edge-to-basal plane-ratios of $\mathrm{MoS}_{2}$ deposited on MWCNTs.

\begin{tabular}{|c|c|c|c|}
\hline & $\begin{array}{r}\text { 1. Peak area } \\
A_{1}\left(Q, C / \mathrm{cm}^{2}\right)\end{array}$ & $\begin{array}{r}\text { 2. Peak area } \\
A_{2}\left(Q, C / \mathrm{cm}^{2}\right)\end{array}$ & $\begin{array}{r}\text { Edge-to-basal } \\
\text { plane-ratio } A_{1} / A_{2}(\%)\end{array}$ \\
\hline ARKM001/MoS $2 \varnothing<8 \mathrm{~nm}$ & 0.040 & 1.421 & 2.8 \\
\hline ARKM002/ $\mathrm{MoS}_{2} 10-20 \mathrm{~nm}$ & 0.013 & 1.292 & 1.0 \\
\hline ARKM004/MoS $240-50 \mathrm{~nm}$ & 0.014 & 1.489 & 0.9 \\
\hline ARKM005/ $\mathrm{MoS}_{2} \varnothing>50 \mathrm{~nm}$ & 0.012 & 1.704 & 0.7 \\
\hline
\end{tabular}

than in the other three samples. Therefore, this sample also obtains the highest edge-to-basal-plane-ratio.

In the following, the current densities of the MWCNT/MoS 2 electrodes were compared with the edge-to-basal-plane-ratios to further study the impact of these ratios on the catalytic property of samples. Figure 12a compares the obtained geometric current density with the edge-to-basal-plane ratio as a function of MWCNT
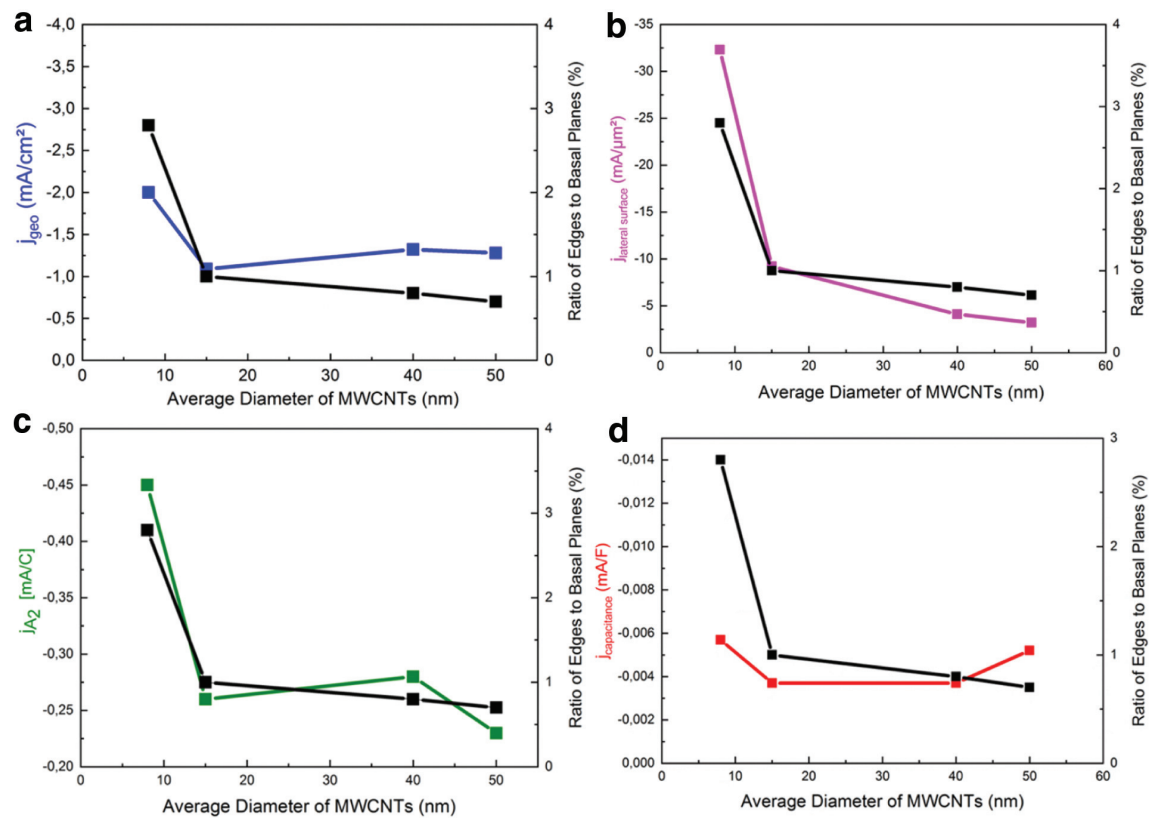

Fig. 12: Comparison the edge-area-ratio as a function of the MWCNTs' diameter with: (a) geometric current density, (b) current density divided by shell surface of the MWCNTs, (c) current density divided by the second peak area, (d) specific capacitance. 
diameter. The sample with the smallest diameter shows the largest current density and the largest edge-to-basal-plane ratio. The left y-axis in Figure 12b visualizes the current divided by the geometric area of the MWCNTs. As expected, the trend of this geometric current density is also consistent with the edge-tobasal-plane ratio. Figure 12c shows the comparison between the current density divided by the area of the second electro-oxidation peak and edge-to-basal planeratio correlating well with each other. In Figure 12d, the comparison of the current density divided by the Helmholtz double layer capacitance $\left(C_{d}\right)$ and the edge-tobasal-plane ratio is shown. The capacitance $C_{d}$ is measured by $\mathrm{CV}$ in a potential region where no electrochemical reaction is occurring. In this region, the capacitive current is proportional to the scan rate $(d f / d t)$ according to Eq. 2 . The unit of the capacitance is As/V or F (Farad) [45].

$$
i_{C}=\frac{d Q}{D t}=\frac{\delta Q}{\delta \varphi} \frac{d \varphi}{d t}=C_{d} \frac{d \varphi}{d t}
$$

In this equation, $i_{c}$ stands for the capacitive current, $Q$ stands for the electric charge, $t$ is the time, and $f$ is the potential, $C_{d}$ stands for the Helmholtz double layer capacitance. As shown in Figure 12d, the edge-to-basal-plane-area ratio and the current densities as a function of capacitance do not correlate, the current divided by capacitance remains constant. The reason could be that MWCNTs have a large electrochemical capacitance which overlays the material-specific capacitance of the $\mathrm{MoS}_{2}$.

From this comparison, one could speculate that the large edge-to-basal-plane ratio in sample ARKM001/MoS 2 is the main reason for its high current density, which leads to a higher number of active sites at the catalyst surface. In summary, HER active $\mathrm{MoS}_{2}$ catalysts should have a high edge-area to van-der-Waals-plane ratio and at the same time a large FWHM in the $\mathrm{E}_{2 \mathrm{~g}}{ }^{1}$ Raman peaks.

\section{Conclusion}

Electrodes made from powders and nanosheets of the molybdenum sulfide phase $2 \mathrm{H}-\mathrm{MoS}_{2}$ have been investigated as hydrogen evolution catalysts under acidic conditions. The catalytic center was identified at the edges of the hexagonal particles. Powders with a diameter $>200 \mathrm{~nm}$ and carbon-supported $\mathrm{MoS}_{2}$ nanosheets were fixed using PEDOT:PSS on conductive glass substrates (FTO). $\mathrm{MoS}_{2}$ nanosheet deposited chemically on MWCNTs of different diameters had sizes in the range from 3 to $5 \mathrm{~nm}$ (particle height in 00.1 direction) and from 10 to $50 \mathrm{~nm}$ (extension of basal planes surrounding MWCNTs in transversal and longitudinal direction). The hydrogen evolution reaction was studied as a function of particle size 
and especially as a function of the edge-to-basal-plane-area ratios of $\mathrm{MoS}_{2}$. MWCNTs of different diameters were tested as support to study their influence on the growth and defects of $\mathrm{MoS}_{2}$ particles. Among all samples, the $\mathrm{MoS}_{2}$ grown on MWCNTs with smallest diameter $(\emptyset<8 \mathrm{~nm})$ obtained the highest catalytic activity $\left(2 \mathrm{~mA} / \mathrm{cm}^{2}\right.$ at $-0.3 \mathrm{~V}$ vs. RHE). By electro-oxidation, the catalytically active edge atoms could be distinguished from the inert atoms on the basal planes. This effect is confirmed by the passivation of edge sites using Tween 80 as surfactant, which mainly protects edge atoms from electro-oxidation. From these measurements, the edge-to-basal-plane ratios in different $\mathrm{MoS}_{2}$ samples could be determined. During the comparison of different electrodes, the sample with highest catalytic activity was found to have the highest edge-to-basal plane-ratio, which means that the high catalytic activity of this sample is due to the high number of active edge atoms on the catalyst non-van-der-Waals surfaces.

Acknowledgment: We like to thank Stefanie Bierwirth, Dipjyoti Das, Dr. Stephan Brunken, Dr. Klaus Ellmer and Karsten Harbauer for their support setting up our sputtering system and performing first electrochemical measurements to characterize hydrogen evolution catalysis using $\mathrm{MoS}_{\mathrm{x}}$ electrodes under acidic conditions. S.F. thanks Dr. Ibrahim Ahmed (HZB) for fruitful discussions. The work became possible due to the continuous and generous financial support in the DFG Priority Program SPP 1613 SolarH2 and by the German Federal Ministry of Education and Research (BMBF) in the project " $\mathrm{H}_{2}$-NanoSolar" (contract no. \# 03SF0353A). We gratefully acknowledge the work of the coordinators at the Technische Universität Darmstadt (SolarH2), Prof. Dr. Wolfram Jaegermann, Dr. Bernd Kaiser and Mrs. Leslie Frotscher.

Funding: Deutsche Forschungsgemeinschaft, Funder Id: http://dx.doi.org/10. 13039/501100001659, Grant Number: FI 1524/4-2.

\section{References}

1. R. R. Chianelli, T. A. Pecoraro, T. R. Halbert, W. H. Pan, E. I. Stiefel, J.Catal. 86 (1984) 226.

2. H. Wang, L. L. Yu, Y. H. Lee, Y. M. Shi, A. Hsu, M. L. Chin, L. J. Li, M. Dubey, J. Kong, T. Palacios, Nano Lett. 12 (2012) 4674.

3. H. E. Sliney, Tribol. Int. 15 (1982) 303.

4. A. R. Beal, W. Y. Liang, J. C. Knights, J. Phys. Part C Solid State Phys. 5 (1972) 3540.

5. S. N. Shirodkar, U. V. Waghmare, Phys. Rev. Lett. 112 (2014) 157601.

6. D. Yang, S. J. Sandoval, W. M. R. Divigalpitiya, J. C. Irwin, R. F. Frindt, Phys. Rev. B 43 (1991) 12053.

7. L. Gmelin, Handbuch der Anorganischen Chemie, C. Winter, Heidelberg (1886). 
8. H. Tributsch, Phys. Chem. Chem. Phys. 81 (1977) 361.

9. T. F. Jaramillo, K. P. Jorgensen, J. Bonde, J. H. Nielsen, S. Horch, I. Chorkendorff, Science 317 (2007) 100.

10. J. Kibsgaard, Z. Chen, B. N. Reinecke, T. F. Jaramillo, Nat. Mater. 11 (2012) 963.

11. D. Kiriya, P. Lobaccaro, H. Y. Nyein, P. Taheri, M. Hettick, H. Shiraki, C. M. Sutter-Fella, P. Zhao, W. Gao, R. Maboudian, J. W. Ager, A. Javey, Nano Lett. 16 (2016) 4047.

12. H. Li, C. Tsai, A. L. Koh, L. Cai, A. W. Contryman, A. H. Fragapane, J. Zhao, H. S. Han, H. C. Manoharan, F. Abild-Pedersen, J. K. Norskov, X. Zheng, Nat. Mater. 15 (2016) 48.

13. T. F. Jaramillo, J. B. Jingdong Zhang, B.-L. Ooi, K. Andersson, J. Ulstrup, I. Chorkendorff, J. Phys. Chem. C 112 (2008) 17492.

14. J. Kibsgaard, T. F. Jaramillo, F. Besenbacher, Nat. Chem. 6 (2014) 248.

15. D. Merki, S. Fierro, H. Vrubel, X. Hu, Chem. Sci. 2 (2011) 1262.

16. J. D. Benck, Z. Chen, L. Y. Kuritzky, A. J. Forman, T. F. Jaramillo, ACS Catal. 2 (2012) 1916.

17. J. D. Benck, T. R. Hellstern, J. Kibsgaard, P. Chakthranont, T. F. Jaramillo, ACS Catal. 4 (2014) 3957.

18. H. Vrubel, D. Merki, X. Hu, Energy Environ. Sci. 5 (2012) 6136.

19. D. Merki, H. Vrubel, L. Rovelli, S. Fierro, X. Hu, Chem. Sci. 3 (2012) 2515.

20. L. R. L. Ting, Y. Deng, L. Ma, Y.-J. Zhang, A. A. Peterson, B. S. Yeo, ACS Catal. 6 (2016) 861.

21. P. D. Tran, T. V. Tran, M. Orio, S. Torelli, Q. D. Truong, K. Nayuki, Y. Sasaki, S. Y. Chiam, R. Yi, I. Honma, J. Barber, V. Artero, Nat. Mater. 15 (2016) 640.

22. F. Xi, P. Bogdanoff, K. Harbauer, P. Plate, C. Höhn, J. Rappich, B. Wang, X. Han, van de R. Krol, S. Fiechter, ACS Catal. 9 (2019) 2368.

23. M. A. Lukowski, A. S. Daniel, F. Meng, A. Forticaux, L. Li, S. Jin, J. Am. Chem. Soc. 135 (2013) 10274.

24. N. McDevitt, J. Bultman, J. Zabinski, Appl. spectrosc. 52 (1998) 1160.

25. C. Chang, S. Chan, J. Catal. 72 (1981) 139.

26. R. N. Bhattacharya, C. Y. Lee, F. H. Pollak, D. M. Schleich, J. Non-Cryst. Solids 91 (1987) 235.

27. Y.-H. Choi, J. Cho, A. M. Lunsford, A.-M. Hashimi, L. Fang, S. Banerjee, J. Mater. Chem. A 5 (2017) 5129.

28. Gitti L. R. T. Frey, Manyalibo J. Matthews, M. S. Dresselhaus, G. Dresselhaus, Phys. Rev. B 60 (1999) 2883.

29. H. J. Conley, B. Wang, J. I. Ziegler, R. F. Haglund Jr., S. T. Pantelides, K. I. Bolotin, Nano Lett. 13 (2013) 3626.

30. M. Guc, J. Andrade-Arvizu, I. Y. Ahmet, F. Oliva, M. Placidi, X. Alcobé, E. Saucedo,

A. Pérez-Rodríguez, A. L. Johnson, V. Izquierdo-Roca, Acta Mater. 183 (2020) 1.

31. B. C. Windom, W. Sawyer, D. W. Hahn, Tribol. Lett. 42 (2011) 301.

32. J. Bonde, P. G. Moses, T. F. Jaramillo, J. K. Norskov, I. Chorkendorff, Faraday Discuss. 140 (2008) 219.

33. D. Kong, H. Wang, J. J. Cha, M. Pasta, K. J. Koski, J. Yao, Y. Cui, Nano Lett. 13 (2013) 1341.

34. D. Y. Chung, S.-K. Park, Y.-H. Chung, S.-H. Yu, D.-H. Lim, N. Jung, H. C. Ham, H.-Y. Park, Y. Piao, S. J. Yoo, Nanoscale 6 (2014) 2131.

35. R. A. DiLeo, B. J. Landi, R. P. Raffaelle, J. Appl. Phys. 101 (2007) 064307.

36. H. Nii, Y. Sumiyama, H. Nakagawa, A. Kunishige, Appl. Phys. Express 1 (2008) 064005.

37. S. R. G. Thakurta, Sa. K. Dutta, J. Phys. Chem. Solids 44 (1983) 407.

38. W. Jaegermann, D. Schmeisser, Surf. Sci. 165 (1986) 143. 
39. B. A. Parkinson, T. E. Furtak, D. Canfield, K. K. Kam, G. Kline, Faraday Discuss. 70 (1980) 233.

40. C. P. Casey, E. L. Paulsen, E. W. Beuttenmueller, B. R. Proft, L. M. Petrovich, B. A. Matter, D. R. Powell, J. Am. Chem. Soc. 119 (1997) 11817.

41. G. Kline, K. Kam, D. Canfield, B. A. Parkinson, Sol. Energy Mat. 4 (1981) 301.

42. T. Sakata, E. Janata, W. Jaegermann, H. Tributsch, J. Electrochem. Soc. 133 (1986) 339.

43. H. S. White, H. D. Abruna, A. J. Bard, J. Electrochem. Soc. 129 (1982) 265.

44. O. Neumüller, H. Römpp, Römpps Chemie-Lexikon, Franckh, Stuttgart, ed 8, (1979-1988).

45. C. H. Hamann, W. Vielstich, Elektrochemie, Wiley-Vch, Weinheim (2005).

Supplementary material: The online version of this article offers supplementary material (https://doi.org/10.1515/zpch-2019-1490). 